\title{
PELATIHAN BUDIDAYA SAYUR DENGAN METODE HIDROPONIK DI DESA GUNTUNG PAYUNG, BANJARBARU
}

\section{Vegetables Cultivation Training with Hydroponic Methods in Guntung Payung Vilage, Banjarbaru}

\author{
Sunardi $i^{*}$ \\ Wiwin Tyas Istikowati ${ }^{2}$ \\ Eny Dwi Pujawati² \\ 'Department of Chemistry, \\ Faculty of Math and Science, \\ Universitas Lambung \\ Mangkurat, Banjarbaru, \\ Kalimantan Selatan, Indonesia
}

2Faculty of Forestry, Universitas Lambung Mangkurat,

Banjarbaru, Kalimantan Selatan, Indonesia

*email: sunardi@ulm.ac.id

\begin{abstract}
Abstrak
Kondisi tanah di desa Guntung Payung yang berawa dengan tanah gambut membuat produktifitas sayuran rendah, perlu pengolahan tanah yang rumit serta konsumsi pupuk yang berlebihan. Perubahab fungsi lahan juga terjadi dan menyebabkan luasan lahan garapan untuk pertanian secara konvensional tidak memadai lagi. Rendahnya tingkat pendidikan dan ketrampilan masyarakat juga menghambat mereka untuk mempelajari dan mencoba hal baru untuk meningkatkan pendapatan keluarga. Oleh karena itu dilakukan pelatihan budidaya sayuran dengan metode hidroponik di desa Guntung Payung. Pelatihan bertani sayuran dengan cara hidroponik bertujuan untuk mendapatkan solusi efektif bagi masyarakat untuk mengatasi kendala pada sulitnya pengolahan lahan gambut. Mitra yang terlibat adalah ibu-ibu rumah tangga yang juga sebagai petani sayuran. Metode yang dilaksanakan adalah pelatihan dan praktik secara langsung di lapangan dengan modul hidroponik, semua peralatan dan bahan-bahan disediakan oleh pelaksana kegiatan, dengan dibimbing oleh pelatih yang sudah berpengalaman di bidangnya. Dengan penguasaan teknologi ini, diharapkan penghasilan mitra akan meningkat dan akan menjadi kelompok petani sayur yang dapat mensuplai kebutuhan sayuran masyarakat Banjarbaru dan sekitarnya. Dari hasil yang didapat, mitra sudah mampu bertani dengan metode hidroponik dan mensuplai kebutuhan sayur untuk keperluan rumah tangganya.
\end{abstract}

Kata Kunci:

Hidroponik

Lahan gambut

Sayuran

Guntung Payung

Pertanian perkotaan

\section{Keywords:}

Hydroponics

Peat land

Vegetables

Guntung Payung

Urban Farming

\begin{abstract}
The soil condition in Guntung Payung village which is swampy with peat soil makes the productivity of vegetables low, it requires complex soil processing and excessive fertilizer consumption. Changes in land function also occur and cause the area of arable land for conventional farming to be inadequate. Low levels of education and community skills also prevent them from learning and trying new things to increase family income. Therefore a hydroponic method of vegetable cultivation training was conducted in Guntung Payung village. Vegetable farming training by means of hydroponics aims to get effective solutions for the community to overcome obstacles to the difficulty of processing peatlands. The partners involved are housewives who are also vegetable farmers. The method implemented is training and practice directly in the field with hydroponic modules, all equipment and materials are provided by the implementers of the activity, guided by trainers who are experienced in their fields. With the mastery of this technology, it is expected that partner income will increase and will become a vegetable farmer group that can supply the vegetable needs of the people of Banjarbaru and its surroundings. From the results obtained, partners have been able to farm hydroponic methods and supply vegetable needs for their household needs.
\end{abstract} https://doi.org//0.33084/pengabdianmu.v4il.378.

\section{PENDAHULUAN}

Desa Guntung Payung termasuk wilayah Kecamatan Landasan Ulin, Kota Banjarbaru, Provinsi Kalimantan Selatan. Desa ini memiliki luas I.252 ha dengan jumlah penduduk 6.348 (Laki-laki: 2.927; Perempuan: 342 I orang). Jumlah penduduk yang berusia produktif yaitu antara 26-59 tahun sebesar 2.484 orang atau $39.13 \%$ dengan tingkat pendidikan masyarakat yang masih rendah. Kelompok tertinggi adalah tingkat SLTA sebesar $28.54 \%$, disusul lulusan SD (18,80\%), SLTP (I5.42\%), pra sekolah (I4,89\%), tidak tamat SD (14,78\%), sarjana (3,93\%) dan terakhir lulusan DI-D3 (3,64\%). Penduduk desa Guntung Payung memiliki 
profesi yang bervariasi antara lain petani, pedagang, buruh, pegawai swasta, PNS, dan TNI Polri. Lokasi desa tergolong strategis dengan jarak ke kota Banjarbaru 6 km dan bandara Syamsudin Noor berlokasi di Desa Guntung Payung. Jalan lintas provinsi melewati desa ini dan menjadi pembatas dengan desa di sebelahnya, yaitu desa Guntung Manggis. Karena letaknya yang strategis membuat desa Guntung Payung memiliki potensi untuk berkembang dengan cepat.

Ketinggian Desa Guntung Payung berada antara 7-25 meter di atas permukaan laut dengan tingkat kelerengan $0-2 \%$. Secara umum, tanah di desa ini merupakan tanah gambut yang stabil dengan tingkat resiko erosi relatif kecil. Kemampuan lahan baik dengan tekstur tanah halus. Dari kondisi ketinggian dari permukaan laut dan kelerengan tanah mengindikasikan wilayah desa ini sangat cocok untuk daerah pertanian, akan tetapi lebih dari $40 \%$ wilayah desa ini adalah rawa dengan tanah gambut atau histosol. Saat ini desa Guntung Payung merupakan sentra pertanian sayur yang mampu mensuplai persediaan sayuran untuk kota Banjarbaru dan sekitarnya.

Dari pengujian pendahuluan oleh pengusul, tanah di daerah Guntung Payung memiliki pH 4 dan tergolong asam. Hal ini sesuai dengan apa yang disampaikan para peneliti yang menyatakan bahwa tanah gambut memiliki $\mathrm{pH}$ antara 3-5. Sementara itu ketika kita akan bertanam sayuran, maka $\mathrm{pH}$ yang paling sesuai adalah 5,6-6,5 (Herwibowo \& Budiana, 2015; Herwibowo \& Budiana, 20I6). Masyarakat desa ini, sebagian besar adalah petani sayuran seperti bayam, kangkung, caisim, terung, tomat dan lainya. Kondisi tanah yang asam merupakan kendala bagi mereka karena memerlukan perlakuan khusus untuk menurunkan kadar asam tanah agar sesuai dengan kondisi yang diperlukan untuk bertanam sayur (Sunardi et al., 20I I; Sunardi \& Istikowati, 20I4).

Kondisi tanah gambut yang pada saat musim kemarau cenderung sangat kering dan pada saat musim penghujan sering mengalami banjir menyebabkan beban biaya yang relatif tinggi pada pertanian sayuran di Guntung Payung karena pemakaian pupuk yang tidak efektif (Sunardi et al., 20l0). Pemupukan yang selama ini dilakukan untuk meningkatkan kesuburan tanah, terutama pada musim penghujan relatif boros karena sebagian besar pupuk hilang yang disebabkan larut dan terbawa banjir sehingga menyebabkan kerugian besar bagi para petani. Sebaliknya, pada musim kemarau diperlukan sistem pengairan dengan metode penyiraman secara rutin menggunakan pompa air untuk menghindari kekeringan yang parah karena sifat tanah gambut yang tidak mampu mengikat air dengan baik sehingga biaya produksi juga meningkat. Meskipun kondisi tanah gambut tidak terlalu menguntungkan untuk bertani sayuran, akan tetapi karena merupakan mata pencarian yang telah dilakukan sejak dulu maka para warga tetap bertahan dengan rutinitas tersebut untuk menopang perekonomian keluarga.

Tujuan dari kegiatan ini adalah untuk meningkatkan pengetahuan masyarakat Guntung Payung Kecamatan Landasan Ulin Kota Banjarbaru tentang sistem pertanian dengan metode hidroponik. Kegiatan ini diharapkan dapat menjadi sarana transfer teknologi sehingga mampu meningkatkan ketrampilan yang akan berdampak pada naiknya pendapatan masyarakat dan kemandirian ekonomi.

\section{METODOLOGI}

Dalam kegiatan ini dilakukan pelatihan budidaya sayuran hidroponik dengan substrat yang akan menggunakan lempung, zeolite, dan biomas sebagai media pengganti perlite. Pelatihan dilakukan pada masyarakat desa Guntung Payung, Banjarbaru, Kalimantan Selatan. Target pelatihan terutama pada lbu-ibu rumah tangga yang juga sebagai petani sayuran. Kegiatan pelatihan dilaksanakan selama 4 bulan, dari bulan Maret sampai bulan Juni 2018 dan dilanjutkan dengan pendampingan hingga bulan Oktober 2018. Metode ini dapat digunakan untuk menanam jenis-jenis sayuran dengan batang keras 
seperti tomat, cabai dan terung, selain itu bisa juga digunakan untuk tanaman berbatang lunak seperti selada, pakcoy, bayam, dan kangkung.

\section{HASIL DAN PEMBAHASAN}

Kegiatan pelatihan budidaya sayuran dengan sistem hidroponik ditujukan kepada warga Kelurahan Guntung Payung yang tergolong produktif (Gambar I). Kegiatan ini diharapkan membuka wawasan mereka untuk menerima informasi dan teknik penanaman yang baru yang bisa diaplikasikan meskipun tidak memiliki lahan yang luas. Dari pelatihan ini, warga merasa mendapat ilmu baru dan dapat memanfaatkan lahan mereka untuk pertanian modern dengan system hidroponik.

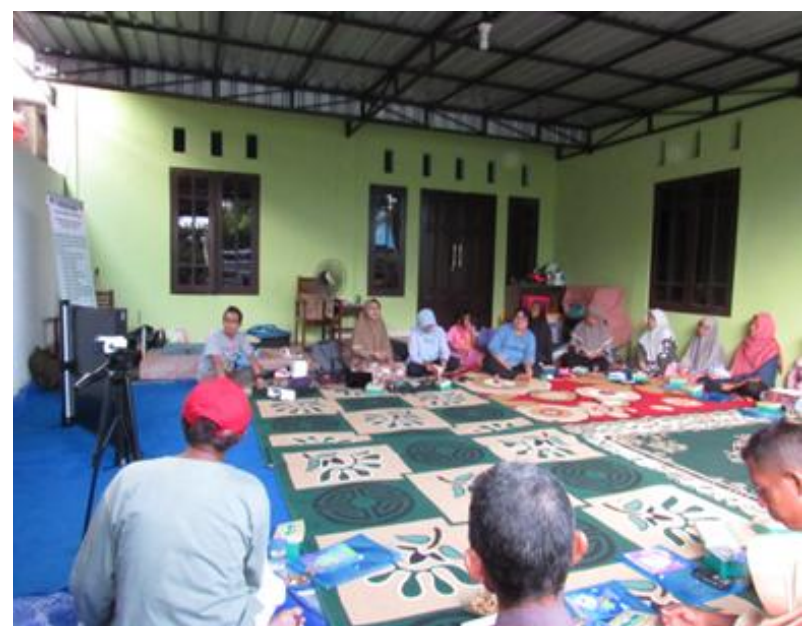

Gambar I. Peserta pelatihan

Kegiatan pelatihan yang dilakukan antara lain adalah sebagai berikut:

Pembuatan Modul Hidroponik

Modul hidroponik dapat dibuat dari talang air, pipa pralon, bak, botol bekas, dan lain-lain. Dalam kegiatan ini, modul dibuat dari pipa pralon. Pembuatan modul dibantu oleh dua mahasiswa Fakultas Kehutanan Universitas Lambung Mangkurat (ULM) (Gusti A. Erfani dan Prima Dunia) yang dilibatkan dalam kegiatan ini sebagai tenaga lapangan. Kedua mahasiswa ahli dalam pengerjaan kayu dan juga pembuatan furniture dari bahan kayu dan logam. Keterlibatan ini, selain melatih mereka dalam pembuatan modul, juga melatih mahasiswa untuk belajar sistem pertanian hidroponik yang bida menjadi bekal mereka di masa depan. Pembuatan modul dilakukan di lokasi mitra sehingga mitra dapat melihat cara pembuatanya dan mendiskusikannya secara langsung (Gambar 2).

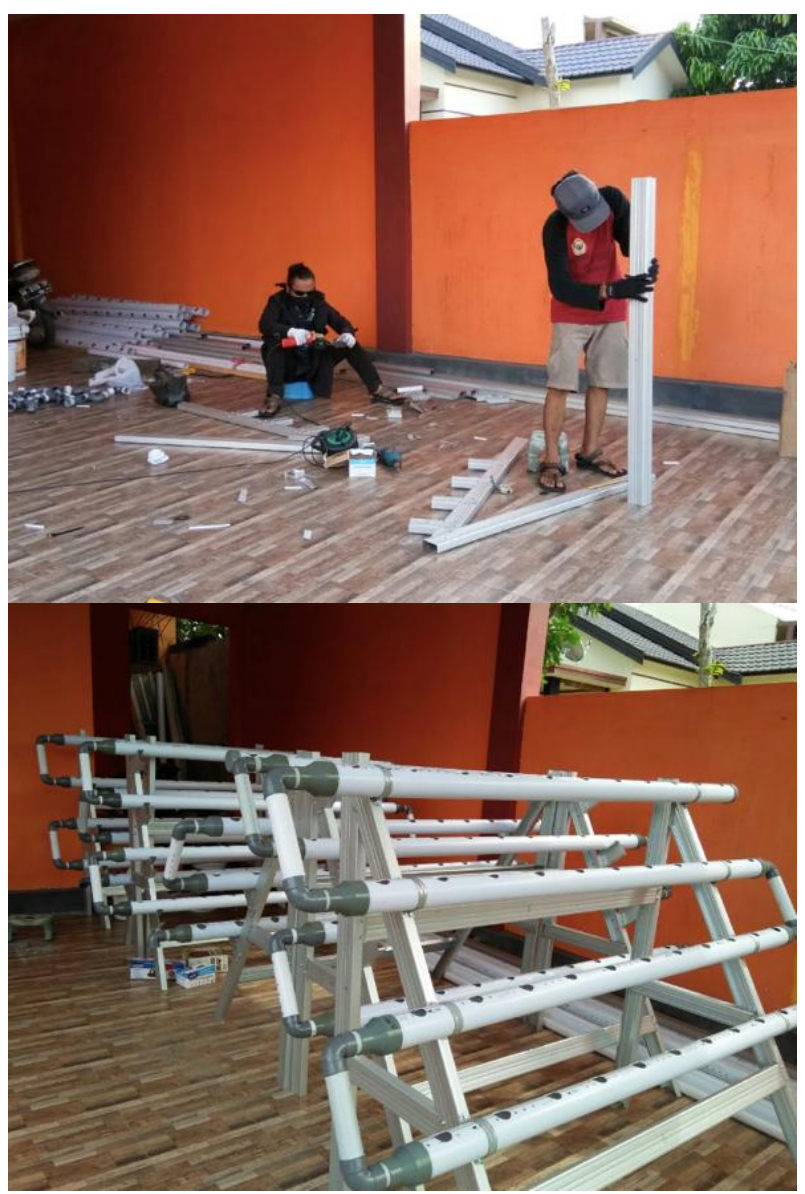

Gambar 2. Pembuatan modul hidroponik (atas) dan hasil modul hidroponik yang telah dibuat (bawah)

Pada pelaksanaan kegiatan ini, tim pelaksana membuat I 2 modul yang diserahkan kepada warga degan ketua RT 07 sebagai koordinator (Gambar 3). Sebagian warga meminta dipasangkan langsung di tembok-tembok rumahnya karena memiliki space yang kosong untuk hidroponik, sebagian berupa modul yang portabel. 


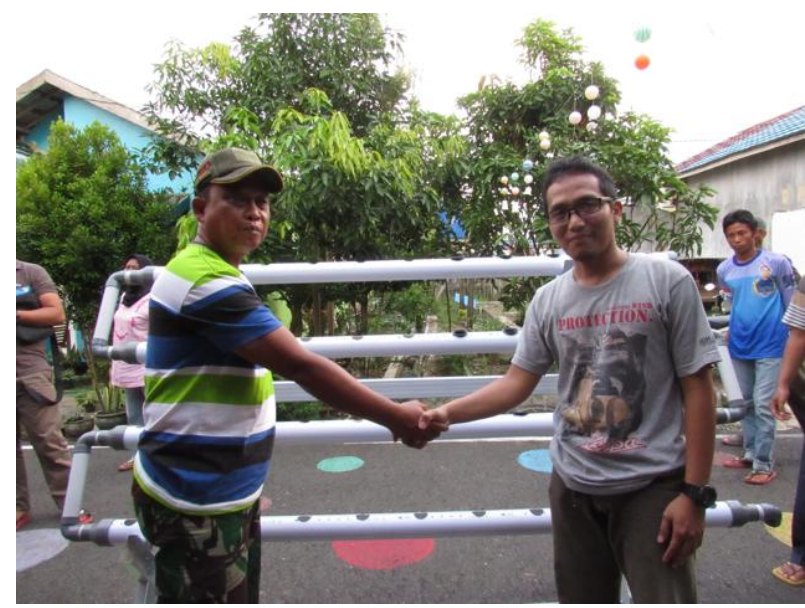

Gambar 3. Penyerahan secara simbolis modul hidroponik

\section{Pembibitan}

Pemilihan benih sangat penting sebagai tolok ukur produktivitas budidaya sayuran secara hidroponik. Pemilihan benih bermutu merupakan langkah awal dalam usaha budidaya secara hidroponik. Beberapa jenis benih sayuran yang bisa dipakai antara lain, benih hibrida, benih lokal, dan benih seleksi lokal. Dalam kegiatan ini benih hibrida akan digunakan karena jenis ini sayuran mampu tumbuh besar, pertumbuhannya seragam dan produktivitas tinggi. Dalam pemilihan benih, cara paling mudah adalah dengan menggunakan air. Benih direndam terlebih dahulu dalam air, benih yang mengapung tidak digunakan karena benih sudah kosong dan meskipun disemaikan tidak akan tumbuh. Penyemaian dilakukan di rockwool kemudian ditutup dengan plastik berwarna hitam selama 12 jam. Biji yang sudah pecah selanjutnya dijemur di bawah matahari selama minimal 6 jam dalam sehari. Bibit yang memiliki sudah memiliki daun sejati atau memiliki 4 helai daun siap disapih ke dalam media tanam.

Ragam media yang digunakan dalam metode ini adalah:

I. Rockwool dibuat dari batu apung yang dipanaskan dan dibentuk serat serta wafer dengan spesifikasi khusus untuk tanaman sayuran dan tanaman hias. Rockwool memiliki kemampuan menahan air dan udara dalam jumlah banyak baik untuk mendukung perkembangan akar tanaman.
2. Zeolit dibedakan menjadi dua jenis, yaitu zeolite sintesis dan alam. Zeolit sintesis adalah jenis material yang dibuat dengan rekayasa ilmiah melalui tahapantahapan prosedur yang cukup rumit dengan menggunakan bahan alumina, silica dan fosfat serta bahan tambahan yang lain. Zeolit alam merupakan jenis mineral zeolit yang langsung diperoleh dari alam. Dalam kegiatan ini, digunakan zeolit alam.

3. Lempung yang dipanaskan dapat digunakan sebagai alternatif media tanam. Seperti media lainnya, media ini berfungsi untuk melekatkan akar. Bulatan-bulatan lempung yang dipanaskan (perlite) memiliki kemampuan menyerap air dan unsur hara yang baik dan juga akan membuat sirkulasi udara dan kelembaban di sekitar akar tanaman lebih baik.

4. Biomassa. Biomasa yang bisa digunakan dalam metode hidroponik antara lain arang sekam dan cocopeat. Arang sekam memiliki kemampuan untuk menyerap dan menyimpan air sebagai cadangan makanan. Cocopeat blok merupakan serbuk sisa pengolahan penguraian sabut kelapa yang dicetak berbentuk kubus. Media ini mampu menyimpan air dengan baik dan sirkulasi udara juga baik.

Penyiapan Nutrisi

Penyiapan nutrisi dalam bertani secara hidroponik merupakan salah satu kunci keberhasilan yang harus diperhatikan. Nutrisi yang yang popular digunakan adalah nutrisi hidroponik $A B$ Mix (Gambar 4). AB Mix merupakan campuran antara pupuk $A$ dan pupuk $B$. Pupuk A mengandung unsur kalium sedangkan B mengandung sulfat dan pospat. Ketiga unsur tidak boleh dicampur dalam keadaan pekat karena tidak bisa terlarut sempurna dan akan menimbulkan endapan yang berakibat pada nutrisi yang diperlukan tanaman tidak dapat terpenuhi secara sempurna. Akar tanaman hanya mampu menyerap nutrisi yang telah terlarut sempurna. Kandungan zat-zat yang ada dalam pupuk $A$ dan pupuk $B$ antara lain 9,9\% $\mathrm{NO}_{3}, 0,48 \% \mathrm{NH}_{4}, 4,83 \% \mathrm{P}_{2} \mathrm{O}_{5}, 16,5 \%$ $\mathrm{K}_{2} \mathrm{O}, 2,83 \% \mathrm{MgO}, \mathrm{II}, 48 \% \mathrm{CaO}, 3,8 \mathrm{I} \% \mathrm{SO}_{3}, 0,0 \mathrm{I} \% \mathrm{~B}$, 
0,025\% Zn, 0,02\% Cu, 0,03\% Mo, dan 0,037\% Fe (Roberto, 2000; Apriyanti, 2015).

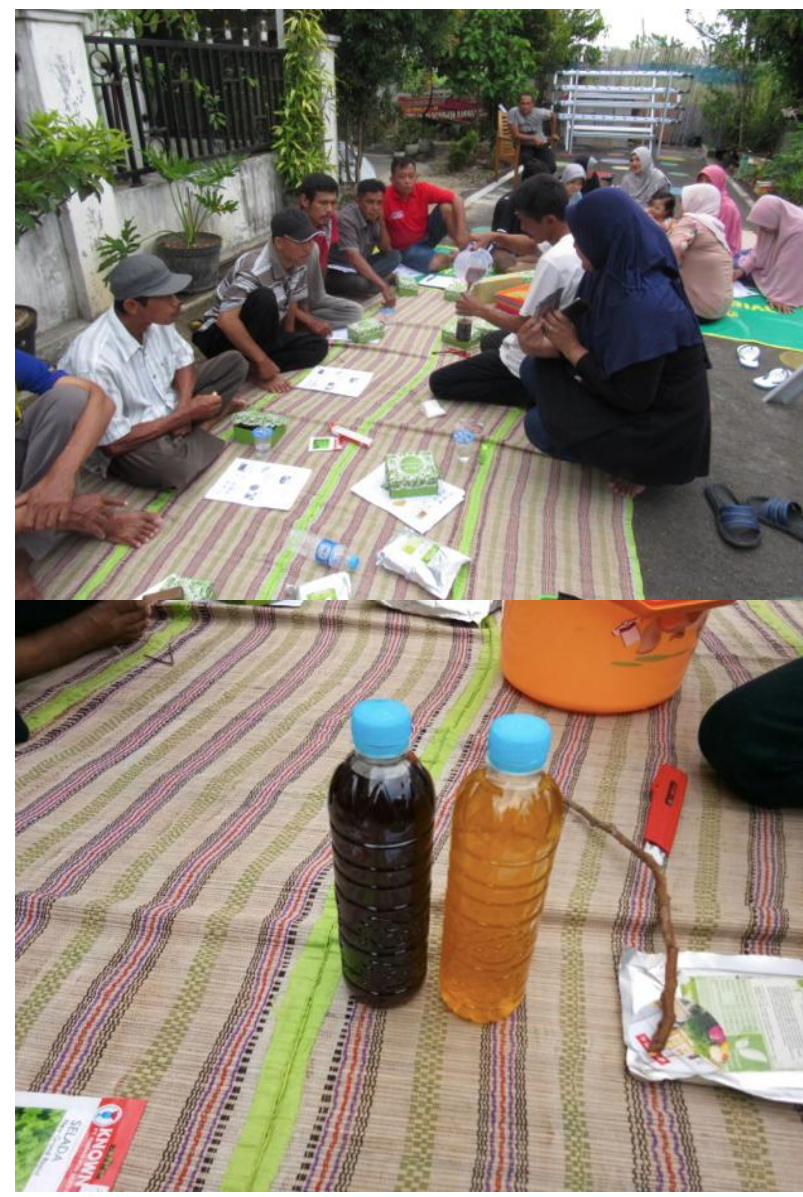

Gambar 4. Proses pembuatan nutrisi hidroponik (atas) dan nutrisi yang telah disiapkan (bawah)

\section{Persemaian}

Pada pelatihan ini, bibit sawi yang digunakan sebagai bahan untuk latihan akan tetapi pelaksana kegiatan menyediakan bibit-bibit yang lain seperti bayam, kangkung, tomat, cabai, dan lain-lain. Bibit sawi dipilih karena mudah dalam penyemaian dan pemeliharaannya. Setelah peserta pelatihan sudah menguasai cara pemeliharaan, mereka mampu mengembangkan sendiri dengan bibit-bibit yang lain dan tipe modul yang beragam. Dari pemilihan benih yang sudah dilakukan selanjutnya benih dimasukkan ke dalam rockwool yang telah dipotong-potong seukuran $2 \times 2 \times 2 \mathrm{~cm} 3$. Rockwool yang telah berisi benih diletakkan di nampan dan ditutup dengan plastik hitam selama 12 jam (Gambar 5).

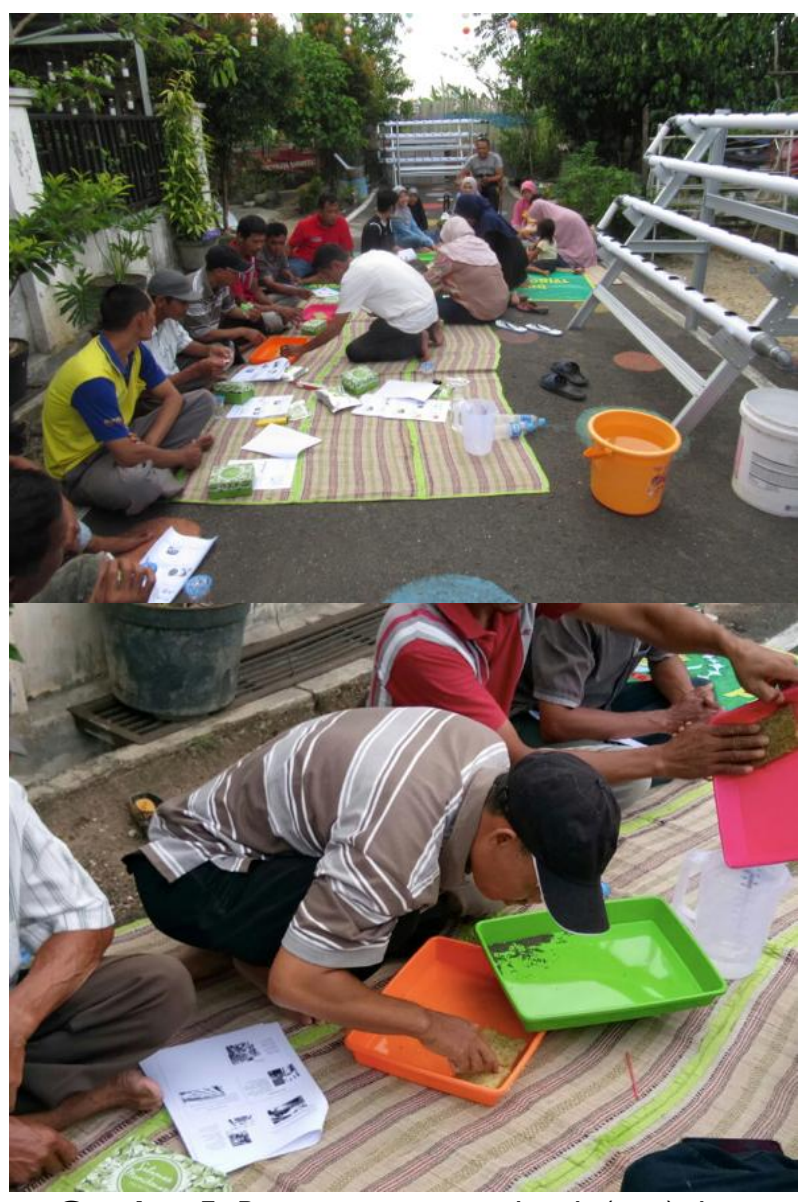

Gambar 5. Proses penyemaian benih (atas) dan pemilihan benih yang akan disemai (bawah)

Penanaman dan Pemeliharaan

Penanaman dilakukan setelah daun sejati muncul. Pemindahan ke dalam modul dilakukan oleh mitra secara mandiri. Metode penanaman dilakukan dengan cara berikut:

I. Memasukkan air pupuk kira-kira $3 / 4$ bagian dari volume pralon,

2. Memasukkan bibit yang sudah tumbuh di pot dengan media tanam sesuai yang ditentakan (zeolite, lempung, dan biomasa),

3. Memasukkan pot yang sudah berisi bibit ke lubang tanam satu persatu hingga terisi semua,

Pemeliharaan

I. Ketika bibit tanaman dipindahkan ke instalasi hidroponik (Gambar 6), pompa harus dinyalakan. Pompa ini bertugas menyalurkan air pupuk melewati selang plastik hingga membasahi media tanam. 
2. Selang harus dijaga agar tidak mampet atau tidak menyalurkan air pupuk. Juga posisi selang harus tetap tertancap ke media tanam. Bila selang plastik lepas dari media tanam, maka media tanam akan mongering sehingga membuat tanaman layu dan mati.

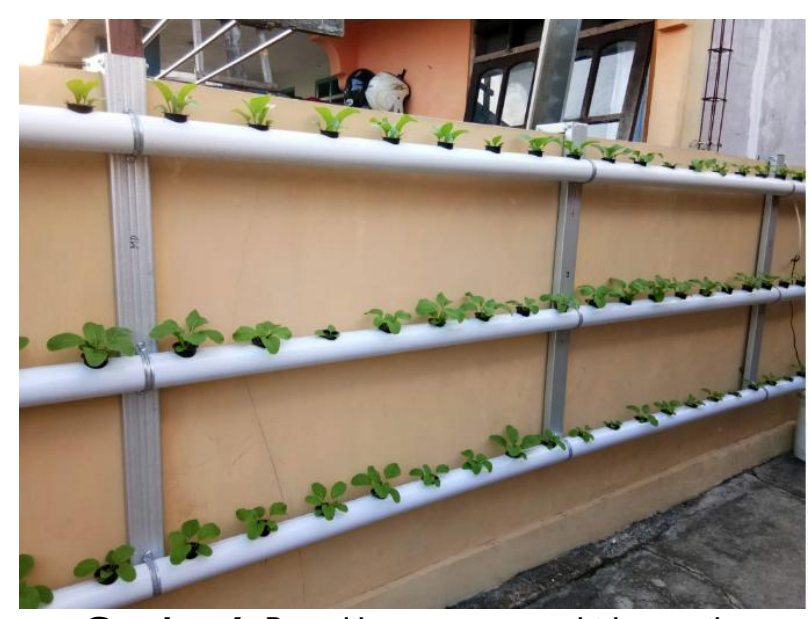

Gambar 6. Pemeliharaan sayuran hidroponik

\section{KESIMPULAN}

Pelatihan pertanian modern dengan sistem hidroponik diharapkan dapat menjadi solusi keberlanjutan usaha pertanian sayuran di lokasi mitra. Dalam hal ini mitra yang merupakan kelompok petani konvensional dapat memiliki keterampilan baru dalam rangka membentuk/mengembangkan masyarakat yang mandiri secara ekonomi. Dari pelatihan yang dilakukan, mitra dari masyarakat desa Guntung Payung sudah menguasai metode bertanam sayuran dengan hidroponik dan mampu mensuplai kebutuhan sayuran keluarganya dengan bertanam sayuran hidroponik. Dengan penguasaan teknologi ini, dalam jangka pendek diharapkan penghasilan mitra akan meningkat dan dalam jangka panjang akan menjadi kelompok petani sayur "urban farming" untuk menggantikan dan atau melengkapi pertanian konvensional yang menghadapi banyak kendala sehingga lokasi mitra tetap dapat menjadi sentra pertanian yang dapat mensuplai kebutuhan sayuran masyarakat Banjarbaru dan sekitarnya.

\section{UCAPAN TERIMA KASIH}

Ucapan terima kasih disampaikan kepada Kementerian Riset, Teknologi dan Pendidikan Tinggi atas pendanaan melalui skim Program Kemitraan Masyarakat tahun 2018 dengan Nomor Kontrak 47/UN8.2/PM/20I8.

\section{REFERENSI}

Apriyanti, R.N. 20I5. Hidroponik Perkotaan. Jakarta: Trubus Swadaya.

Herwibowo, K. \& Budiana, N.S. 20I5. Hidroponik Sayuran. Jakarta: Penebar Swadaya.

Herwibowo, K. \& Budiana, N.S. 2016. Hidroponik Portabel. Jakarta: Penebar Swadaya.

Roberto, K. 2000. Hydroponics, Future Garden. New York: Inc. Farmingdale.

Sunardi, Arryanto, Y., Sutarno, \& Irawati, U. 2010. Adsorpsi Asam Giberelin Pada Kaolin Teraktivasi Asam. Indonesian Journal of Chemistry. 10(3):320-26.

Sunardi, Arryanto, Y., Sutarno, \& Irawati, U. $201 \mathrm{I}$. Kaolin Modified with Cationic Surfactant for Gibberellic Acid Carrier Material. Indonesian Journal of Chemistry. I I (I):96-102.

Sunardi \& Istikowati, W.T. 20|4. Sintesis Polimer Superabsorben Dari Alang-Alang (Imperata Cylindrica) Dan Pemanfaatannya Sebagai Slow Release Pupuk Untuk Mendukung Pertanian Lahan Basah Di Kalimantan Selatan. Laporan Penelitian. Banjarbaru: Universitas Lambung Mangkurat. 